\title{
MULTIPLICATION DU TRYPANOSOMA CRUZI DANS LE SANG PÉRIPHÉRIQUE DE LA SOURIS PAR PASSAGES SUCCESSIFS. \\ RECHERCHE DE LA PRÉMUNITION VIS-A-VIS DES SOUCHES HOMOLOGUES ET HÉTÉROLOGUES
}

\author{
Par MUHTAR DARMAN
}

La virulence du Trypanosoma cruzi, qui est très variable suivant les souches considérées et suivant leur généalogie, a été étudiée en igr3 par mon maître, le prof. E. Brumpt, qui a démontré que la virulence exaltée par de nombreux passages peut être ramenée à son état initial, par passage chez les invertébrés vecteurs. D'autre part, H. Galliard, en 1930 , a démontré que la virulence d'une souche donnée n'est pas modifiée par la splénectomie pratiquée avant ou pendant l'évolution de la maladie. Emmanuel Dias, d'après ses expériences, a prétendu avoir obtenu des infections très intenses, en inoculant dans les tissus, du cinquième ou dixième jour, du sang contenant des flagellés récemment formés.

Nous avons voulu augmenter la virulence de deux souches de Trypanosoma cruzi, l'une dite Téhuantépéc, rapportée du Mexique (avec les triatomes infectés de la région de Téhuantépéc) par le prof. Brumpt pendant son voyage de r 938 . Nous sommes partis du sang d'une souris inoculée dans le péritoine avec des déjections de triatome infecté. Le sang de cette souris présentait $2-3$ parasites par champ. L'autre, dite Vickersæ, a été envoyée de Hambourg par le $D^{\mathrm{r}}$ Martin Mayer en 1935 avec des triatomes infestants. Depuis cette époque, le virus est conservé sur souris, Rhodnius et triatomes. Nous sommes partis du sang d'une souris infectée avec le broyat d'intestin du Rhodnius prolixus $33{ }_{7}$ A.H. Nous avons inoculé toutes les souris par la voie péritonéale, avec le sang prélevé à l'œil d'une autre souris infectée précédemment. Cette méthode, plus pratique et plus commode, mérite d'être expliquée. Elle a l'avantage de donner du sang en quantité suffisante presque instantanément, tandis que la prise du sang faite au niveau de la queue, abstraction faite du temps qu'elle demande, n'est pas capa-

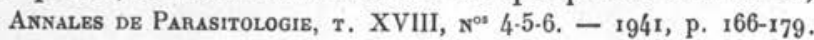


ble de donner suffisamment de sang pour inoculer plusieurs animaux en même temps. On prend directement le sang à l'aide d'une pipette Pasteur à l'angle interne de l'œil de la souris. Pour ceci il faut : $\mathrm{I}^{\circ}$ une pipette Pasteur stérile de $\mathrm{I} \mathrm{mm} .5$ de calibre (si elle est plus étroite le sang se coagule très vite et bouche la pipette, si elle est plus large on risque de tuer l'animal); $2^{\circ}$ un verre à pied stérilisé ; $3^{\circ}$ une solution de citrate de sodium à I p. Ioo, stérile. Après avoir tout préparé, on procède de la manière suivante : on met dans le verre stérile quelques centimètres cubes de solution citratée indiquée plus haut, on trempe dans la solution la pipette, qui se remplit par capillarité avec une goutte de la solution qui va empêcher la coagulation immédiate du sang. On prend une souris de la main gauche et on tient en même temps les oreilles, le dos et la queue, puis on enfonce de la main droite la pipette dans l'angle interne de l'œil. Pour faciliter l'entrée du sang dans la pipette, on doit faire à son extrémité, à l'aide d'une pince, une petite encoche. Il ne faut pas trop appuyer sur l'œil, sans quoi l'animal peut mourir. Le sang pénètre dans la pipette et après avoir obtenu une quantité suffisante, on retire la pipette et on en souffle le contenu dans le verre à pied contenant la solution citratée. Par cette méthode on peut obtenir autant de sang qu'on veut. Toutefois, il ne faut pas dépasser $0 \mathrm{~cm}^{3} 5$ parce que l'animal peut mourir. Le sang cesse de s'écouler automatiquement, l'opération ne laisse aucune suite; le'lendemain on ne remarque rien sur l'œil opéré. Le Trypanosoma cruzi peut rester vivant dans la solution citratée à la température du laboratoire pendant plus de deux heures. Un autre avantage de cette méthode est qu'après quelques jours on peut reprendre du sang au même ánimal et sur le même œil sans aucun risque.

Passages avec les parasites inoculés dans le sang périphérique. - D'après le prof. Brumpt, lorsqu'on inocule à un animal neuf le sang d'un animal infecté, les trypanosomes passent quelques heures sous la forme trapue du flagellé dans la circulation. D'après E. Dias, si le sang inoculé est riche en parasites il faut 40 minutes pour la voie sous-cutanée, et 2 h. 45 pour la voie péritonéale (chien $79^{5-720}$ gr.). Le passage est aussi. très rapide après inoculation intramusculaire ou intracérébrale (C. Chagas fils). E. Dias donne le nom de phase sanguine initiale à cette phase de l'infection durant laquelle les trypanosomes sont trouvés précocement dans la circulation. D’après lui, chez les chiens, après l'inoculation péritonéale, les parasites disparaissent au bout 24 heures, et on ne les voit plus jusqu'à nouvelle reproduction. Dans nos expériences, nous avons inoculé les souris blanches par voie intrapéritonéale à la dose de $0 \mathrm{~cm}^{3} 5$ de sang présentant $\mathrm{I}-2$ parasites 
par champ, et dilué 5 fois avec une solution de citrate de sodium à I p. 10o. Donc, le sang employé n'était pas riche en parasites. Pour cette raison, nous n'avons constaté après 10-12 heures, que la présence de rares parasites dans chaque préparation, sauf au cours du $5^{\mathrm{e}}$ passage où, en inoculant du sang plus riche, nous en avons trouvé au bout de 4 heures dans la circulation. Cette phase initiale sanguine durait (quand elle existait, car nous ne l'avons pas toujours rencontrée)

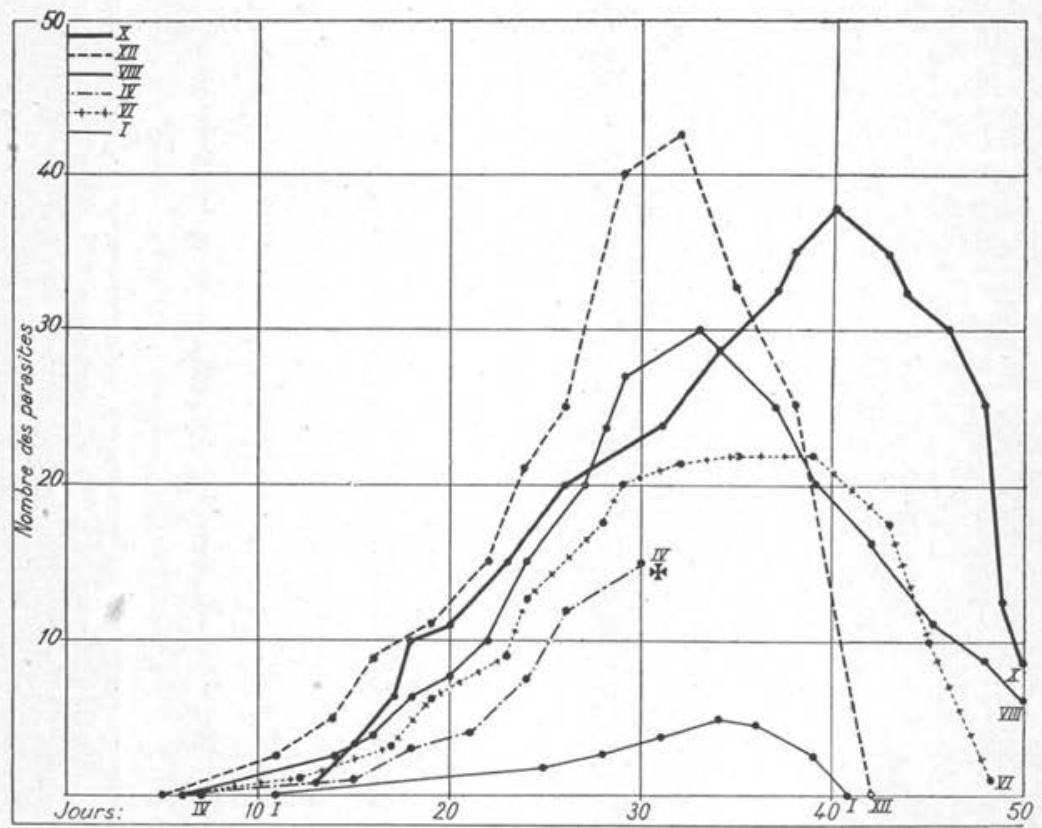

Graphique r. - Souche Téhuantépec. - Augmentation du nombre des trypanosomes . dans le sang périphérique des souris, au cours des passages $1,4,6,8$, I0, 12.

2-3 jours, sans modification du nombre des parasites. Au bout de ce temps les parasites disparaissaient. La reproduction de nouveaux parasites commençait, suivant les passages, du $5^{\mathrm{e}}$ au $10^{\mathrm{e}}$ jour après l'inoculation. Le moment de la réapparition des parasites dans le sang devait être à la fin de la période d'incubation d'après E. Dias. Les premiers parasites qui passaient dans le sang étaient des formes jeunes très minces et très mobiles que l'on ne voyait plus au bout de quelques jours, malgré l'augmentation du nombre des flagellés dans le sang. $I^{\mathrm{er}}$ passage. - L'apparition des parasites jeunes a commencé à 
partir du $10^{e}$ jour de l'inoculation ( 1 p. roo champs); le lendemain il n'y avait pas une augmentation sensible, 2 jours après i p. 50 champs ; une semaine après I p. 25 champs ; ${ }^{\mathrm{e}}$ semaine, ${ }^{\mathrm{I}-2}$ par champ; le $34^{\mathrm{e}}$ jour, les préparations étaient au maximum de richesse, 5 parasites par champ (graphique I). Puis le nombre des parasites commença à diminuer : ro jours après on en trouvait I pour 5 champs. La diminution continuait à se faire graduellement : au bout de 3 mois il n'y avait plus de parasites dans le sang périphérique.

$2^{\mathrm{e}}$ passage. - L'allure de l'infection était presque la même que pour la première, mais chez aucune des souris l'augmentation n'a dépassé 2-3 par champ et, comme précédemment, au bout de trois mois les parasites n'existaient plus dans le sang périphérique.

$3^{\mathrm{e}}$ passage. - Rien de plus que précédemment.

$4^{\mathrm{e}}$ passage. - L'allure de l'infection a changé : la période d'incubation, c'est-à-dire la réapparition du parasite, a commencé à partir du $7^{\ominus}$ jour et, au bout d'un mois, le nombre des parasites dans le sang était de r 5 par champ. Cette souris, qui avait plus de parasites que les autres, est morte (graphique 1 ) en ayant ${ }_{1} 5$ parasites par champ. Les quatre autres souris, qui n'ont jamais dépassé 5 parasites par champ, ont continué à vivre; au bout de deux mois on comptait un parasite pour 5o-6o champs.

$5^{\mathrm{e}}$ passage. - Nous avons inoculé du sang ayant des parasites à raison de 12 par champ et dilué 5 fois. L'infection était très caractéristique. Nous avons constaté les flagellés dans le sang 4 heures après l'inoculation et l'apparition des formes jeunes (fin de la période d'incubation) s'est produite le $6^{e}$ jour. L'augmentation des parasites a été rapide : une semaine après, deux souris en avaient déjà I par champ, et au $38^{\mathrm{e}}$ jour, l'une d'elles en avait 25 , une autre en avait $\mathrm{r} 8$ et les trois autres en avaient 8-i5 par champ. Toutes les souris que nous avons inoculées sont mortes à quelques jours d'intervalle, en succombant toujours pendant le maximum de l'infection. Donc, nous n'avons pas pu garder ces souris guéries pour ce passage.

$6^{\mathrm{e}}$ passage. - Le maximum de parasites dans le sang, qui est apparu le $35^{\mathrm{e}}$ jour (graphique $\mathrm{r}$ ) de l'inoculation, donnait 22 parasites par champ; comme allure de l'infection rien de plus que pour les passages précédents, il n'y a pas eu de mort.

$7^{\mathrm{e}}$ passage. - Nous n'avons pas eu beaucoup de parasites, à peine I 2 par champ. Il n'y a pas eu de mort, l'infection était très bénigne.

8 passage. - La période d'incubation a été de 6 jours, comme précédemment, avec cette seule différence qu'une des souris a eu 3 o parasites par champ au $33^{\circ}$ jour de l'infection, et qu'une est morte 
en ayant 20 parasites par champ, avec une anémie intense. Les autres, qui en avaient 20-22 par champ, ont guéri dans les 75 jours.

$9^{\mathrm{e}}$ passage. - Bien que nous ayons inoculé des souris du même. élevage et du même âge avec la même proportion de parasites, nous n'en avons eu que 15 par champ. Pas de changement de la durée de la période d'incubation et de l'infection sanguine. Il n'y a pas eu de mort, même nous pourrions croire que notre souche avait perdu

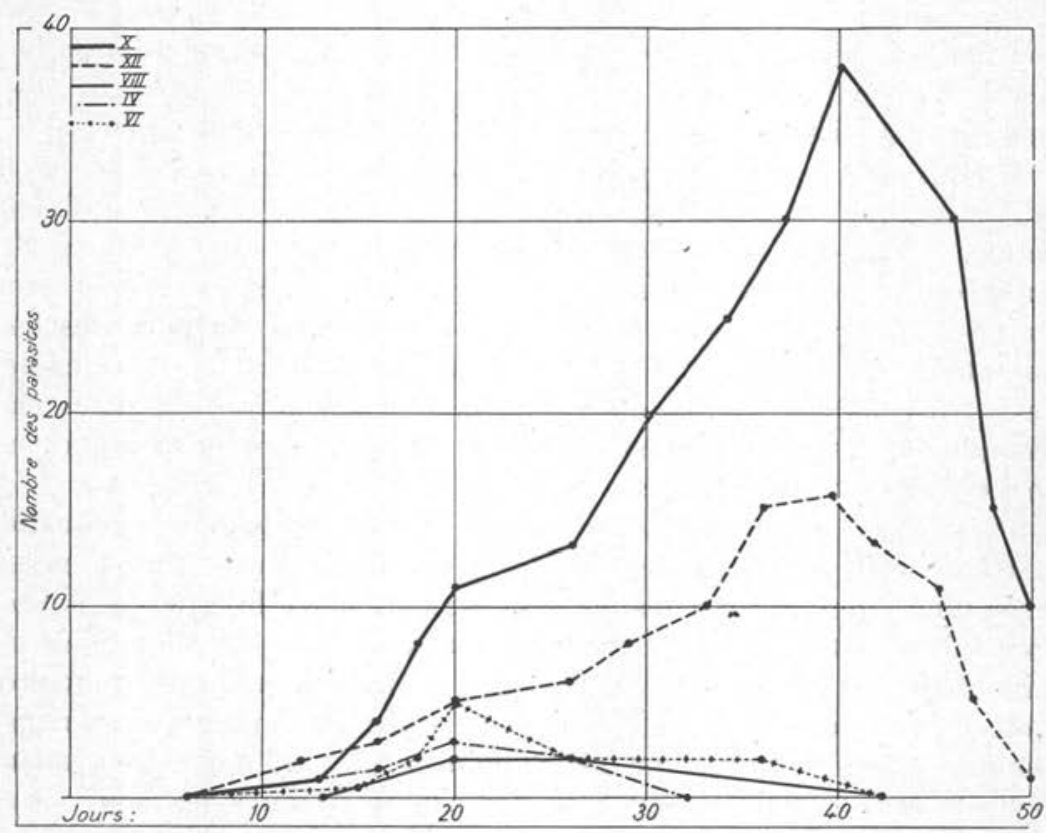

Graphique 2. - Souche Téhuantépec. - Variations du nombre des parasites dans le sang périphérique des souris au cours du $10^{\circ}$ passage.

sa virulence, si nous n'avions pas constaté la multiplication du virus dans le passage ultérieur.

$I 0^{\mathrm{e}}$ passage. - La période d'incubation a été de 6 jours et l'une des souris a eu 38 parasites (graphiques $\mathrm{I}-2$ ) par champ au $40^{\mathrm{e}}$ jour. Pas de mort et au bout de deux mois toutes les souris avaient I parasite pour too champs, sauf celle qui en a eu 38 et en avait 'encore 2 à ce moment-là.

$I I^{\mathrm{e}}$ passage. - La période d'incubation a été de 5 jours. L'une des souris a eu au $38^{\mathrm{e}}$ jour 40 parasites par champ, et elle les a gardés à 
peu près dans la même proportion pendant 4 jours, et le $9^{\circ}$ jour, elle en avait 4 par champ. Donc, quoique la multiplication du virus dans le sang ait demandé au moins 35-40 jours pour cette souche, la diminution du nombre des parasites, au contraire, s'est faite en 4-5 jours (graphiques $\mathrm{I}-2$ ). Les autres souris de ce passage ont eu 20-25 parasites par champ; même l'une d'elles, malgré qu'elle ait eu 28 flagellés au $2 \mathrm{I}^{\mathrm{e}}$ jour de l'inoculation, s'est débarrassée complètement de ses parasites au bout de deux mois sans avoir eu d'augmentation.

$I_{2}{ }^{\mathrm{e}}$ et dernier passage. - Nous avons constaté comme période d'incubation, 5 jours, et l'une des souris, au bout du $29^{\circ}$ jour, avait déjà 40 parasites par champ; après deux jours, le nombre des parasites a dépassé 4o, à tel point qu'il nous a été impossible de les compter. L'animal souffrait d'une anémie intense, au point que sur la préparation fraiche, on voyait presque autant de parasites que d'hématies. Les poils hérissés, elle était dans un état cachectique prononcé, elle se nourrissait difficilement. Mais elle a résisté à l'infection et a survécu ; 3 jours après, les flagellés n'étaient plus que 25 par champ. Après une semaine, elle en avait I pour 2 champs (graphique I). Une autre souris de ce passage a eu, au bout du $28^{\circ}$ jour, 25 parasites par champ et mourut le même jour. Nous avons fait des coupes avec son cœur, qui était bourré de formes Leishmania, qu'on peut considérer comme la cause de la mort. La mort de cet animal nous a conduit à cette réflexion; que le nombre de parasites dans le sang périphérique n'est peut-être pas proportionnel au nombre de parasites dans les viscères.

Nous avons constaté 8 morts parmi 80 souris soit io p. Ioo, dont 3 à leur mort avaient $20-35$ parasites par champ, deux autres en avaient r5-20, l'une ro, et les 2 dernières à peine 3 parasites. Tandis que I 6 souris sur 80 , soit 20 p. Ioo, ont eu i5-4o parasites par champ sans mourir. Chez quelques-unes de ces dernières, nous avons mème constaté la suppression complète des parasites dans le sang périphérique. Abstraction faite de leur résistance individuelle, nous voulons attribuer la résistance à l'infection de ces dernières souris à la moindre infection des viscères, malgré l'augmentation énorme du nombre des parasites dans le sang périphérique. En effet, nous avons toujours constaté un grand nombre de parasites (forme Leishmania) dans les préparations par apposition et les coupes faites avec les cœurs des souris mortes.

Chez 5 souris, qui sont devenues pleines après l'inoculation ou l'ont été dans les premiers jours avant l'inoculation, l'infection a eu une allure très bénigne. Elles n'ont jamais eu plus de 5 parasites par champ dans leur sang et la disparition des parasites, surtout après la naissance 
des petits, s'est produite très vite. Après deux mois, on ne voyait plus de flagellés dans leur sang.

A chaque passage, nous avons inoculé des souris à divers âges : ce sont les jeunes qui ont eu des parasites, mais pas toujours beaucoup. D'autre part, dans un même passage, entre souris du même élevage et du même àge, il y avait une différence d'infection énorme (graphique 2). L'une avait 38 parasites par champ, l'autre en avait I-2, Peut-ètre ceci provient-il du nombre de flagellés inoculés, malgré que nous ayons injecté à chaque souris la mème quantité de sang. Les parasites n'étaient peut-être pas disséminés uniformément dans le sang, ou bien la quantité de parasites était la même et la différence peut-être expliquée par la résistance individuelle. Finalement, en examinant le graphique $\mathrm{I}$, on remarquera que d'une part le nombre de parasites augmente avec le nombre de passages; d'autre part que la période d'incubation, qui était de ıo jours, s'est fixée à 5 jours; de plus, la mortalité de ro p. ioo que nous avons obtenue pour cette souche prouve que l'augmentation du virus dans le sang n'est pas parallèle à celle du pouvoir pathogène du virus.

La souche Vickersæ. - Nous sommes partis, comme nous l'avons dit plus haut, du sang de souris infectées par le broyat d'intestin de Rhodnius prolixus 337 A.H., ayant 13 parasites par champ.

$I^{\text {er }}$ passage. - Après l'inoculation intrapéritonéale de la même dose que dans les expériences précédentes, nous avons constaté quelques heures après des flagellés dans le sang périphérique (phase sanguine initiale), probablement à cause de la richesse du parasite dans le sang injecté. Trois jours après on ne voyait plus les flagellés et la réapparition du parasite (forme jeune) n'a commencé qu'au $\mathrm{I}^{\mathrm{e}}$ jour, un peu plus tardivement que précédemment, malgré la richesse en parasites du sang injecté. L'augmentation du nombre des parasites était aussi sensiblement lente. Au $40^{\circ}$ jour, l'une des souris a eu ${ }_{1} 5$ parasites par champ; les autres en eurent 4-ro. Mais, contrairement à l'augmentation qui fut lente, la diminution fut rapide. Chez les souris moins infectées, au bout du $50^{\circ}$ jour, on ne voyait plus les trypanosomes dans le sang. Celle qui en avait $\mathrm{r} 5$ par champ n'en avait plus au $70^{\circ}$ jour. Tandis que, dans la précédente souche, la disparition du parasite dans le sang n'était obtenue qu'au bout de trois mois.

$2^{\ominus}$ passage. - Rien d'extraordinaire sauf que le nombre des parasites s'est élevé jusqu'à 20 par champ.

$3^{\mathrm{e}}$ passage. - La période d'incubation est de 6 jours et, au bout d'un mois, l'une des souris avait déjà 3o parasites par champ, l'augmentation est plus rapide que dans l'expérience précédente où le 
nombre maximum de parasites n'a jamais été avant le $35^{\mathrm{e}}$ jour (graphiques $\mathrm{I}-3$ ). La diminution aussi était rapide; après dix jours, il n'y avait qu'un parasite pour 20 champs.

$4^{\mathrm{e}}$ passage. - Rien de plus que précédemment.

$5^{\mathrm{e}}$ passage. - La période d'incubation a été de 6 jours, le nombre de parasites s'est élevé à 38 par champ au bout de 32 jours (graphique 3).

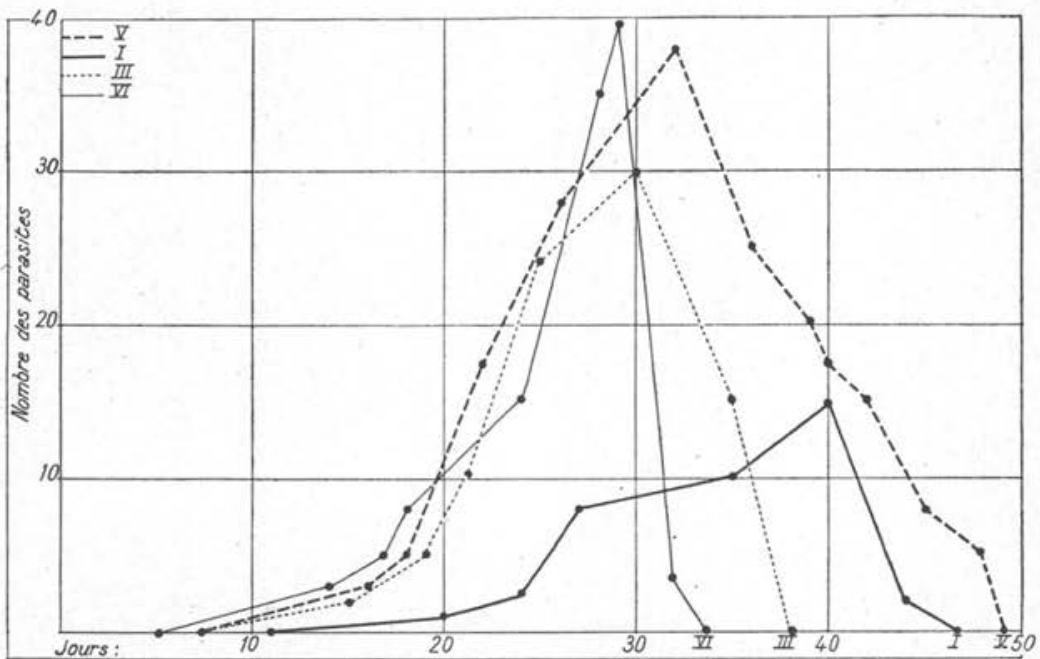

GraphiQue 3. - Souche Vickersæ. - Augmentation du nombre des trypanosomes dans le sang périphérique des souris, au cours des passages $\mathbf{x}, 3,5,6$.

$6^{\text {e }}$ et dernier passage. - L'allure de l'infection était la même, mais une des souris, au bout de 29 jours, a eu 40 parasites par champ (graphique 3 ) et, chose curieuse, après 3 jours, elle en avait 2 (diminution subite que nous n'avons constatée qu'une seule fois).

Dans cette souche, nous avons constaté les caractères suivants qui la différencient de la précédente : $\mathrm{I}^{\circ}$ Pas de mortalité parmi $4 \mathrm{I}$ souris que nous avons inoculées ; $2^{\circ} \mathrm{A}$ partir du $3^{\mathrm{e}}$ passage, l'augmentation, puis la disparition du virus était très rapide (graphique 3 ) dans le sang; $3^{\circ}$ Disparition complète du virus chez 25 souris, au bout de deux mois ; $4^{\circ}$ Chez les souris très infectées, la disparition du virus n'a jamais dépassé aussi $7^{0}$ jours. Les caractères que nous venons de citer montrent que cette souche pullule très vite, mais qu'elle est moins pathogène pour les souris blanches, que la souche précédente. Nous 
voyons donc une discordance entre la pullulation du parasite dans le sang périphérique et le pouvoir pathogène pour l'animal.

Recherches de l'immunité partielle vis-à-vis des souches homologues chez les souris infectées par le Trypanosoma cruzi. - Nous nous sommes servis pour notre expérience de souris plus ou moins guéries : les unes complètement, du moins apparemment, ne contenant

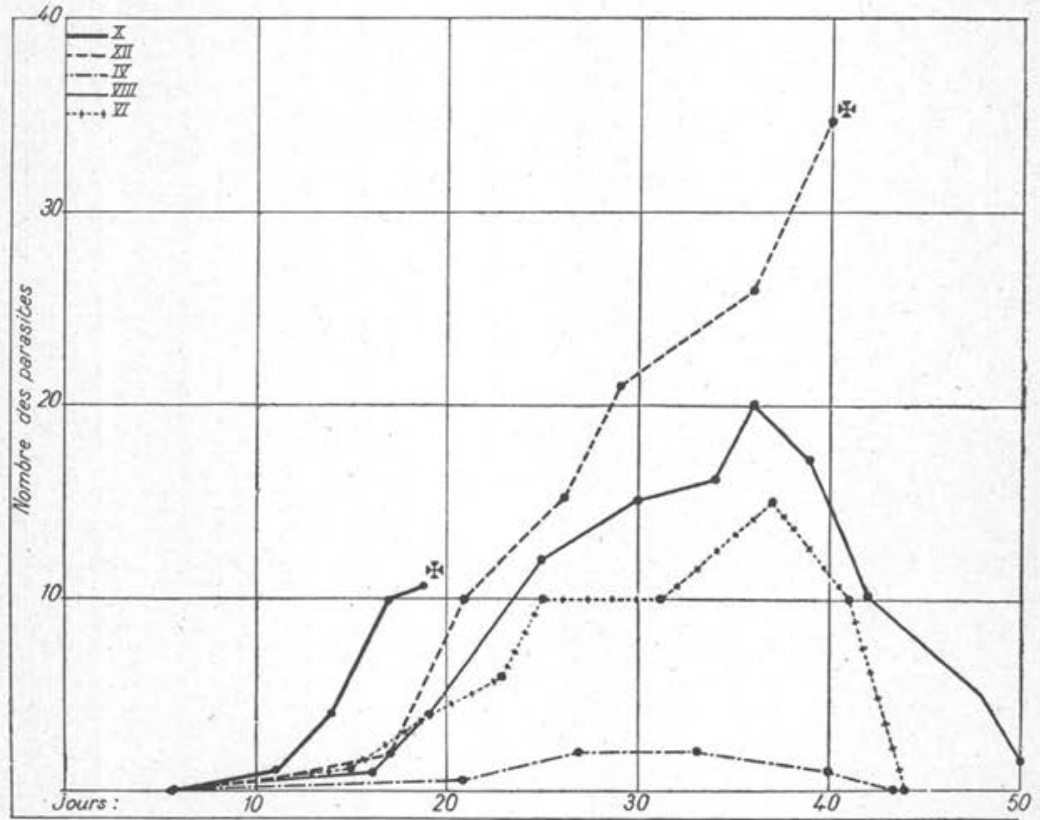

GrapHIQUe 4. - Souche Vickersæ. - Variations du nombre des parasites dans le sang périphérique des souris, au cours du $6^{\circ}$ passage.

aucun parasite dans le sang périphérique, les autres partiellement guéries présentaient un parasite pour 80-100-r5o champs.

La question a été résolue définitivement pour la souche hétérologue par mon maître, le prof. Brumpt, qui a démontré, sur ig souris préalablement infectées, que l'infection avec une souche Trypanosoma cruzi donnait, après six mois, une résistance à une autre souche du mème parasite.

Nous avons repris la même expérience en commençant d'abord par la même souche. Nous avons pris dix souris infectées par la souche Téhuantépéc $\left(6-\mathrm{I} 2-\mathrm{I} 939 ; 4-\mathrm{I}-\mathrm{I} 9^{3} 9 ; 2 \mathrm{I}-\mathrm{I}-\mathrm{I} 9^{3} 9\right.$ et du $\mathrm{I}^{\mathrm{er}}-2^{\mathrm{e}}-3^{\mathrm{e}}$ passa- 
ges), deux ont été complètement guéries ; l'examen ne nous a jamais révélé de flagellés dans le sang périphérique; les 8 autres avaient un parasite pour 80-100- 150 champs. Nous les avons inoculées le 28-4-1 939 , en même temps que 5 témoins, chacune avec $0 \mathrm{~cm}^{3} 5$ de sang prélevé dans l'œil de deux souris du $8^{\circ}$ passage de la même souche (Téhuantépéc) ayant 25 parasites par champ. Avant d'inoculer le sang, contrairement à la méthode précédente, où nous avions dilué 5 fois, nous l'avons dilué 2 fois, afin de pouvoir inoculer beaucoup de parasites. Les témoins ont été infectés à partir du $6^{\circ}$ jour et l'une des souris est morte après i 9 jours avec ro parasites par champ. Dans des frottis du cœur, par apposition, nous avons trouvé la forme Leishmania (graphique 4). $\mathrm{Au} 40^{\circ}$ jour, une autre ayant 35 parasites par champ est également morte et par apposition du cœur même constatation (de la forme Leishmania). Les trois autres, qui ont eu plus de 20 parasites par champ, ne sont pas mortes. Trois mois après, deux d'entre elles ont complètement guéri, la dernière avait encore un parasite pour 40-5o champs. Quant aux souris préalablement infectées (immunisées?), voici ce que nous avons constaté chez elles : celles qui étaient complètement guéries n'ont jamais eu de trypanosomes dans leur sang après réinoculation; parmi les autres plus ou moins guéries (ayant un parasite pour $80-150$ champs), 5 souris ont $\mathrm{eu}$ au $\mathrm{II}^{\mathrm{e}}$ jour un parasite pour I O-I 2 champs, et les trois autres, le même jour, en avaient à peine un pour $25-5$ o champs, mais elles n'ont pas présenté de formes jeunes de parasites. Cette légère augmentation du virus n'a pas duré longtemps, deux jours après, elle a déjà commencé à diminuer et au $20^{\circ}$ jour, le nombre des parasites a été ramené à son état initial. Au $25^{\circ}$ jour, parmi les 8 souris, 4 ne présentaient plus de parasites dans leur sang. Il semble que la réinfection a facilité leur guérison, abstraction faite de l'augmentation très faible du nombre des parásites chez les 8 souris. D'ailleurs cette augmentation peut être mise sur le compte non pas de la réinfection mais simplement d'un afflux vers le sang périphérique des anciens parasites, cachés dans les viscères, sous l'influence de la réinfection, car, chez les deux souris complètement guéries, nous n'avons jamais vu, après réinoculation, le parasite dans leur sang. Nous pouvons dire que si elles avaient, sinon une immunité complète, au sens propre du mot, vis-à-vis de la souche homologue, elles avaient du moins, d'après les témoins, une résistance remarquable,contre la même souche.

Mêmes expériences sur les mêmes souris avec la souche Vickersæ. - Après un mois, nous avons voulu réinoculer les souris infectées deux fois par la souche Téhuantépéc, avec la souche Vickersæ 
Par cette expérience, nous voulions savoir : I $^{\circ}$ si le Vickersæ élait différent du Téhuantépéc; $2^{\circ}$ s'il est différent, quelle sera la réaction des souris ayant une résistance assez forte contre l'une des souches de $T$. cruzi.

Nous avons repris les dix souris, dont deux lors de la première réinoculation avec la souche homologue n'ont jamais eu de parasites dans le sang périphérique. Et, parmi les 8, quatre souris qui étaient guéries ou ne présentaient plus de parasites. Donc, au commencement de l'expérience, nous avions six souris n'ayant pas de parasites

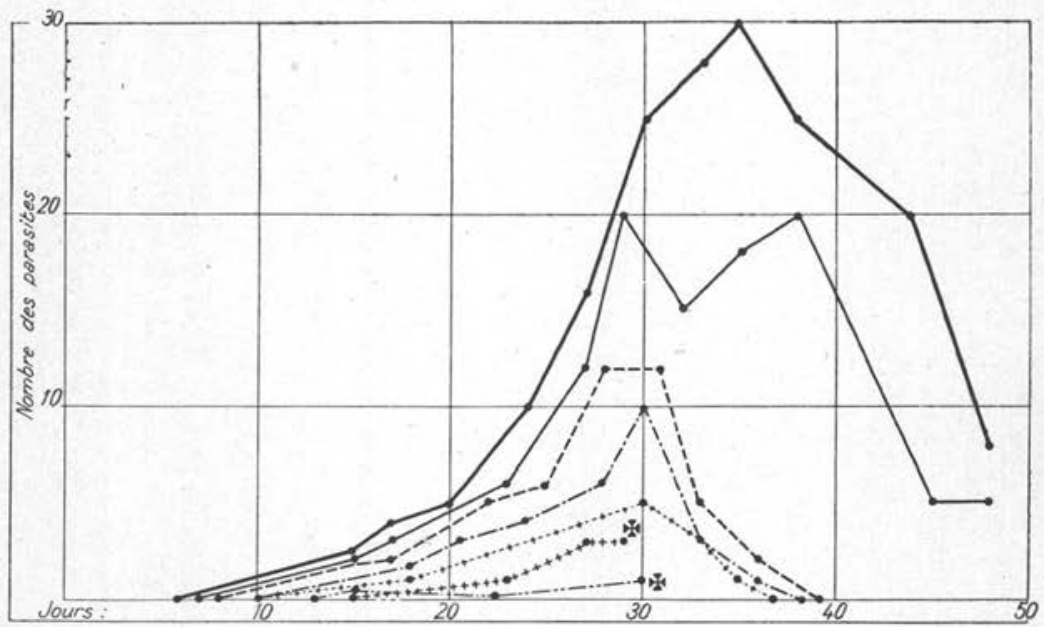

GraphiQue 5. - Réinfection, avec la souche Vickersæ, des souris immunisées par la souche Téhuantépec.

dans le sang périphérique. Les 4 autres, comme dans la première expérience, en avaient infiniment peu (I pour roo champs). Nous les avons réinoculées le 28-5-1 939 , par la voie intrapéritonéale, en même temps que 5 souris témoins, du même âge et du même élevage, avec le sang prélevé de l'œil des deux souris du $4^{\mathrm{e}}$ passage de la souche Vickersæ, dont l'une d'elles avait 25 parasites par champ, et l'autre, I 2. Le sang a été dilué 2 fois avec la solution de citrate de sodium à I p. roo, c'est-à-dire que le nombre des parasites dans le sang injecté a été réduit à 6-7 par champ. Chez les témoins, à partir du $5^{\circ}$ jour, le nombre des parasites a commencé à augmenter et, au bout d'un mois, l'une des souris en avait 28-3o (graphique 5) et l'allure de l'infection 
était exactement la même que celle constatée pendant le passage que nous avons décrit plus haut. Il n'y a pas eu de mort.

Observation des souris réinfectées. - Nous avions six souris indemnes de parasites. Deux de ces souris ont eu à peine un parasite pour 1 5-2o champs, qu'elles ont gardés pendant io jours en nombre à peu près égal. Puis, le nombre des flagellés est tombé à I pour 8o-roo champs. Les 4 autres souris, dont 2 n'ont jamais présenté de parasites dans le sang après la première réinoculation de la souche homologue, n'ont eu à aucun moment de flagellés dans le sang.

L'observation des 4 'souris restant sur les dix souris étudiées nous a montré : l'une d'elles est morte au bout du $28^{\circ}$ jour avec 3 trypanosomes par champ (graphique 5). Une autre souris est également morte au $30^{\mathrm{e}}$ jour de l'infection en ayant un parasite pour deux champs (graphique 5). Les autres souris, qui ont eu un parasite pour 2-10 champs pendant le premier mois de l'infection, les ont gardés à peu près dans la même proportion pendant deux mois après l'inoculation, présentant 3-4 rechutes. Finalement, le nombre des flagellés a diminué et au $75^{\mathrm{e}}$ jour elles en avaient très peu, un pour 100-150 champs. A l'autopsie des deux souris mortes, nous n'avons rien constaté pouvant expliquer la mort, seules les appositions du cœur se sont révélées assez riches en forme Leishmania. Mais, comme elles n'ont pas eu beaucoup de parasites dans leur sang et que d'autre part elles étaient dans un état cachectique, à cause des réinoculations répétées, on peut attribuer leur mort à une autre cause que la réinfection par la souche Vickersæx.

En dehors de cette hypothèse que nous ne pouvons démontrer, il y a une chose évidente, c'est que : $\mathrm{I}^{\circ}$ à part les 4 souris qui n'étaient pas infectées, les six autres étaient plus atteintes que dans la première expérience faite avec la souche homologue; $2^{\circ}$ l'infection a duré longtemps et son allure n'est pas du tout la même que la première, elle était plus traînante. Les souris ont gardé plus de deux mois les trypanosomes, en nombre plus ou moins restreint dans leur sang; $3^{\circ}$ elles ont maigri énormément, malgré que les conditions dans lesquelles elles étaient entretenues n'aient pas changé.

Nous voulions savoir si la souche Vickersæ était différente de celle de Téhuantépéc. Les trois caractères de cette infection que nous venons de citer peuvent bien prouver que Vickersæ est une souche différente de celle de Téhuantépéc. Quant à la question de résistance vis-à-vis de la souche hétérologue, elle nous a amené aux constatations suivantes : $1^{\circ}$ La souche Vickers $x$ est une souche moins pathogène, puisque ni pendant le passage, ni chez les témoins nous n'avons jamais eu de cas mortel; $2^{\circ}$ Malgré que nous ayons eu deux cas mortels, d'ailleurs douteux, en nous basant sur les quatre souris qui 
n'ont jamais eu de flagellés dans leur sang, nous pouvons dire qu'elles avaient une résistance plus ou moins marquée vis-à-vis de la souche hétérologue, mais que cette résistance était beaucoup moins marquée que pour la souche homologue.

\section{RÉSUMÉ}

Les passages successifs que nous avons faits avec le Trypanosoma cruzi de Téhuantépéc et la souche Vıckersæ sur les souris nous ont montré que l'augmentation du nombre des trypanosomes dans le sang périphérique est possible. Avec la première souche, au bout de I 2 passages, nous avons obtenu plus de 40 parasites par champ. Avec la souche Vickersæ, nous avons obtenu le même chiffre au bout de 6 passages.

Virulence. - Les résultats de notre expérience sur les deux souches nous permettent de dire que la virulence, ou plutôt le pouvoir pathogène du virus, n'est pas lié au sens propre du mot à la quantité de flagellés dans le sang périphérique. Il dépend plutôt de la souche même. En effet, nous avons obtenu presque autant de parasites dans le sang avec Vickersæ et avec Téhuantépéc, cependant ce dernier donnait ro p. roo de mortalité, tandis qu'avec l'autre souche la mortalité était nulle. De plus, la mortalité avec la souche Téhuantépéc n'a pas été régulière : au cours du cinquième passage, 5 souris sont mortes avec $3-25$ parasites par champ, tandis qu'au ${ }_{12}{ }^{e}$ passage, des souris qui en avaient 15 -40 et même davantage ont résisté, sauf l'une d'entre elles qui est morte avec 25 parasites par champ. Au contraire, celle qui en avait plus de 40 a résisté. D'après les résultats de l'expérience sur l'immunité croisée vis-à-vis de la souche Téhuantépéc et de la souche Vickersæ, nous avons constaté : $\mathrm{r}^{\circ}$ que les souris infectées avec la première souche avaient, quatre mois après l'inoculation, une résistance remarquable vis-à-vis de la même souche ; $2^{\circ}$ que les 2 souches étaient différentes l'une de l'autre; $3^{\circ}$ que les mêmes souris réinfectées après un mois avec Vickersæ ont montré vis-à-vis de cette souche une résistance plus ou moins marquée.

\section{BibLiographie}

Brumpt (E). - Précis de Părasitologie. Paris, Masson et $\mathrm{C}^{\mathrm{ie}}, 5^{\circ}$ édition, 1936.

- Immunité partielle dans les infections à Trypanosoma cruzi. Transmission de ce trypanosome par Cimex rotundatus. Rôle régulateur des hôtes intermédiaires. Passage à travers la peau. Bull. Soc. path. exot., VI, 19r3, p. 173 . 
Diss (E.). - Le Trypanosoma cruzi pendant les premières phases de l'infection expérimentale. C. R. Soc. Biol., CX, $\mathrm{r}_{932}, \mathrm{n}^{\circ} \mathrm{r} 8$.

Galliard (H.). - Envahissement précoce et intense de la cavité abdominale chez les souris au cours des infections à Trypanosoma cruzi. Ann. de Parasit., VII, 1929 , p. 377 .

- Localisation péritonéale exclusive au cours de certaines infections à Trypanosoma cruzi chez la souris. Ann. de Parasit., VIII, r93o, p. 140.

Laveran (A.) et Mesnil (F.). - Trypanosomes et Trypanosomiases. Paris, Masson et $\mathrm{C}^{\mathrm{ie}}, \mathrm{rg} \mathbf{2}$.

Institut de Parasitologie de la Faculté de Médecine de Paris (Directeur : Professeur E. Brumpt). 